\title{
PASTURE FOR DEER PRODUCTION
}

Abstract

Diversification in agriculture has seen the establishment of new enterprises such as deer farming. While still a small industry in absolute terms the deer industry is growing rapidly.

The utilisation in situ of pasture by deer is discussed in relation to their feed requirements for two types of farming $\mathbf{V} \mathbf{Z}$. weaner production and a 15 month venison stag operation. Seasonal feed requirements are poorly aligned with average pasture growth with both types of farming being characterised by surplus spring pasture and a deficit during summer and autumn.

The primary constraint to increased on-farm production is the summer deficit. It is suggested that alternative pasture species with improved summer growth characteristics be examined. It is also argued that earlier calving and the use of larger terminal sires could ease the pressure on summer pature and more closely align feed requirements of deer with pasture growth.

Keywords: Farmed deer, red deer, pasture growth. pasture intake, feed requirements, calving date, terminal sire.

\section{INTRODUCTION}

Grassland farming in New Zealand is largely based on sheep and cattle with mating timed to produce offspring in late winter/earlyspring. By this means annual feed requirements can be aligned with the seasonal forage supply. However, the newer agricultural enterprises such as deer farming can bring different challenges.

Although deer are farmed throughout New Zealand, $60 \%$ are confined to the North Island and of these $39 \%$ come within the Waikato, Thames Valley and Bay of Plenty regions. Much of that land area has a potential stock carrying capacity of $>20$ stock units per ha (Ball \& Field 1984).

Red deer, fallow and wapiti, in common with most deer species, are seasonal breeders. However, within the seasonal pattern red deer have a less synchronous calving than fallow deer but with an earlier onset in late spring (Asher 1985). Red and fallow deer seldom produce other than single offspring which are most usually weaned after about 100 days of lactation immediately pre-rut (March-April). Consequently, opportunities for extended flushing of females before mating are limited.

A seasonal pattern of feed intake and growth is characteristic of male red and fallow deer at pasture up to 27 months (Adam \& Asher 1986). Most weight gain is made over spring/summer and little, if any, over winter. With older stags there is a marked depression in feed intake over the rut which is reflected in body weight losses of up to $25 \%$ in fallow bucks (Asher 1985) and 30\% in red stags. Changes in the body weight of hinds are less pronounced. Clearly the seasonal pattern of demand for pasture by various classes of deer differs greatly from that of sheep and cattle.

This paper examines problems associated with the utilisation in situ by deer of ryegrass/white clover pastures.

\section{RECOMMENDED FEEDING LEVELS}

\section{Seasonal feed requirements}

Information on feed or energy requirements for specified performance levels of different classes of deer is necessary for making decisions on feeding levels. Based on relationships between liveweight gain and metabolisable energy (ME) intake (Fennessy, Moore \& Corson 
1981) requirements have been recalculated (Table 1) for milder North Island conditions and farming systems involving:

- production and sale of weaners

- 15 month venison

\section{Pasture allowance}

Only limited published information exists on post-grazing pasture mass (Giles 1984) and on relationships between pasture allowances and pasture intakes for deer. However, it has been shown that rising 6 month old red stags on 7-day allocations each require a pasture allowance equivalent to $5 \mathrm{~kg}$ DM/day to achieve daily liveweight gains of $200 \mathrm{~g}$ over autumn (Figure 1). As yet data for pre-grazing pasture mass are not available in relation to dry matter intakes by deer. However, subjective observation of the grazing behaviour of red and fallow deer suggests such information might be required for developing successful grazing strategies.

Table 1: Seasonal metabolisable energy (ME) requirements for mixed-aged/(MA) hinds and stags aged 4 to 16 months

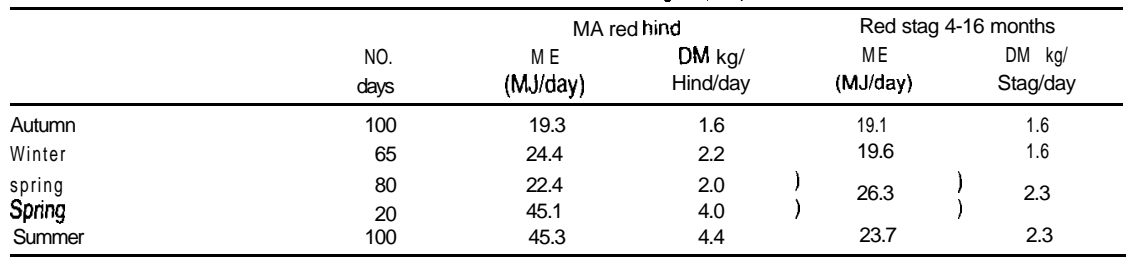

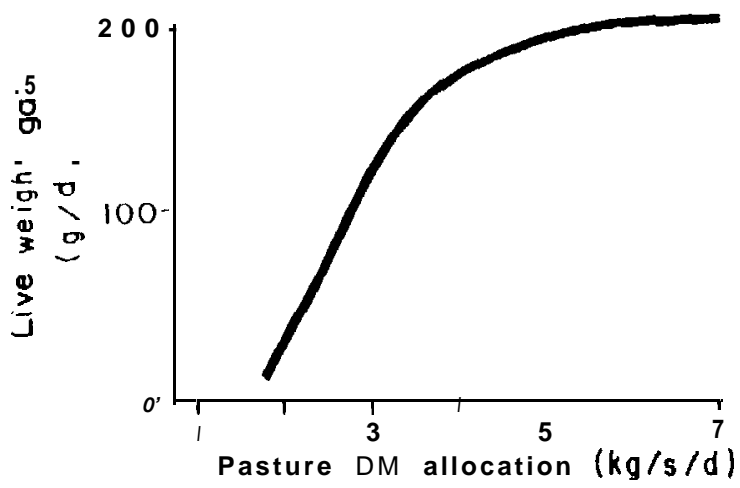

Figure 1: Growth responses of weaner red deer stags to changes in pasture allowance over autumn (Adam and Asher 1966).

\section{FEED SUPPLY AND DEMAND}

Variations in pasture growth arise between years and seasons and are well documented. However, variations in rotation length can allow some reallocation of feed from one period for grazing in situ in a later period of lower pasture growth (Rattray 1977). Thus the pattern of feed supply is not completely controlled by the timing of pasture growth. Consequently comparing deer feed requirements with pasture growth may not fully reflect constraints to deer production.

\section{Stocking rate}

While annual pasture production dictates maximum stocking rate, the combination of seasonal pasture growth and stocking level can determine the onset, duration and amount of likely feed deficits or surpluses. Generally the feed demands associated with a 15 month 
venison production system appear poorly aligned with pasture growth (Figure 2). Such a system is characterised by a surplus of spring pasture and a deficit of high quality summer/autumn pasture, While an increae in the overall annual stocking rate can reduce the extent of the spring surplus it is also likely to exacerbate pasture deficits over summer and autumn (Figure 2).

Higher stocking rates reduce daily gains of newly weaned stags over autumn (Table 2). The reduction in growth rate over autumn amounted to $15.6 \pm 4.2 \mathrm{~g} / \mathrm{stag} /$ day $(P<0.05)$ for each additional stag carried. A gross margin analysis of these data suggest an optimum stocking rate of between 16 to 20 stags per ha grazing from 3 to 14 months of age for pastures yielding over $11000 \mathrm{~kg} \mathrm{DM}$ (Adam et al. 1986). Appropriate ways to control surplus spring pasture need to be found in view of the apparent association between spring pasture management and maintenance of a photosynthetically active summer sward (Baars et al. 1981).

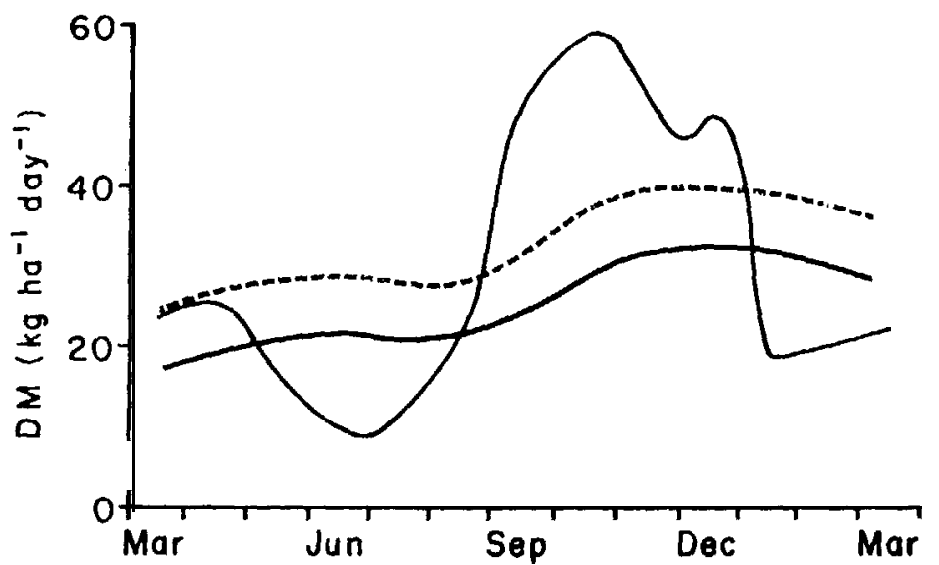

Figure 2: Annual pattern of pasture growth at Hamilton (Baars 1976) and feed requirements of $12(-\rightarrow)$ and $16(--)$ stags

Table 2: Effect of stocking rate on weight gains of newly weaned red deer stags during autumn

\begin{tabular}{lccccccc}
\hline & & Year & & \multicolumn{3}{c}{ Stocking rate (stags/ha) } \\
& 1 & 2 & SED & 16 & 20 & 24 & Sig \\
\hline $\begin{array}{l}\text { Daily gain } \\
\text { (g/day) }\end{array}$ & 143 & 110 & 13.7 & 158 & 135 & 97 & \\
\hline
\end{tabular}

\section{Dale of calving}

The increase in feed requirements of red deer hinds after calving is not closely aligned with the rapid increase in spring pasture growth seen in ryegrass/white clover swards (Figure 3). In the case of fallow does, which fawn several weeks later, the situation is worse. Overall, there is little scope to increase the annual stocking rate as a means of utilising the flush of spring pasture. Such action would put additional pressure on pasture over summer, a period noted for generally low and highly variable pasture growth rates related to moisture stress and/or high summer temperatures (Baars 1976).

Calving in red deer hinds, in response to a naturally occurring oestrus and the rut, can nearly be completed during the month of November. However, even earlier calving, by in excess of 1 month, may be possible by manipulating fertility with the hormone melatonin Such an action would not only result in a closer alignment between peak spring pasture production and median calving date but may also allow generally higher annual stocking rates. 


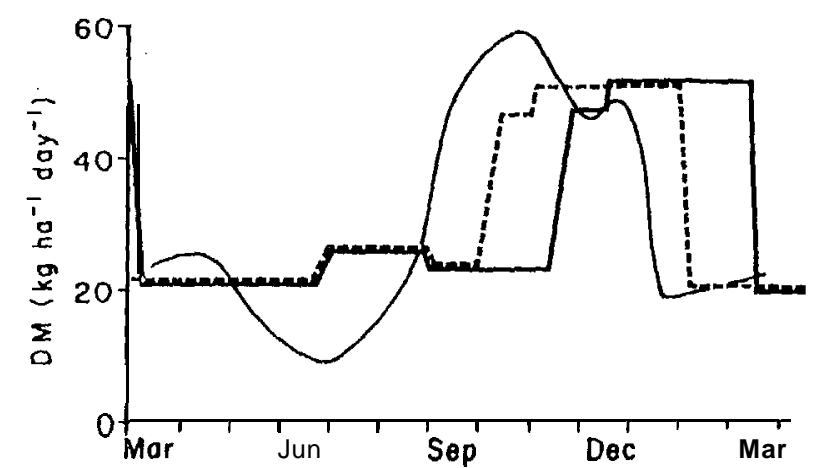

Figure 3: Annual pattern of pasture growth at Hamilton (Baars 1976) and the feed intake required by 12 hinds tha calving in October (--) and November (-).

\section{CONSTRAINTS TO ON-FARM PRODUCTION}

A number of differences in patterns of feed demand exist between deer and traditional livestock. These arise due to the late onset of calving and the seasonal pattern of liveweight growth. Whereas pasture growth exceeds the feed demands of deer over spring, the reverse occurs over summer and autumn. Consequently, summer pasture growth appears the primary constraint to increased on-farm production. Further constraints due to ryegrass staggers and facial eczema can also be present during autumn.

The primary constraint of summer pasture growth can be approached by increasing pasture growth or reducing the feed demand. It remains to be seen whether grasses such as prairie grass (Grasslands Matua) or cocksfoot (Grasslands Wana) can effectively increase the feed available for deer over summer.

It has already been seen that advancing the date of calving can result in a better alignment between pasture growth and feed demand. However, grazing pressure applied to pastures over summer can also arise from an overlap between rising 15 month stags, not yet at market weight, and the need to conserve pasture for on-coming March weaned animals. While earlier calving might reduce this overlap another approach is that of mating a proportion of red hinds to larger terminal sires. Offspring from matings involving the elk and wapiti hybrid sires can greatly reduce the time taken to slaughter and also reduce the pressure on summer pasture. These latter options would, in addition, increase the demand in situ for spring pasture. Even so control of spring pasture is essential and requires additional stock, such as cattle, and/or conservation on a proportion of the farm.

\section{Reterences}

Adam J.L., Asher G.W. 1986. Deer growth and production. Proceedings of a Deer Course for Veterinarians No. 3: 8-16.

Adam J.L.. Asher G.W., Sandrey R.A. 1986. Growth and venison production: Red and tallow deer. Proceedings Ruakura Farmers Conference 5-9.

Asher G.W. 1965. Reproduction of farmed fallow deer (Dama dama L.). Proceedings of a Deer Course for Veterinarians No. 2. $107-125$.

Baars J.A. 1976. Seasonal distribution of pasture production in New Zealand IX Hamilton. NZ Journal of Experimental Agriculture 4: 157-I 61.

Baars J.A., Jagusch K.T.. Dyson C.G., Farquhar P.A. 1981. Pasture production and sward dynamics under sheep grazing. Proceedings NZ Society Animal Production 42: 101-111.

Ball P.R., Field T.R.O. 1964. Productivity and economics of legume-based pastures and grass wards receiving fertiliser nitrogen in New Zealand. In Barnes R.F., Ball P.R., Brougham R.W., Marten G.C., Minson D.J. (MS). Forage Legumes for Energy $\rightarrow$ Efficient Animal Production. Proceedings of Trilateral Workshop, Palmerston North.

Fennessy P.F., Moore G.H., Corson I.D. 1981. Energy requirements of red deer. Proceedings NZ Society of Animal Production 41: 167-173.

Giles K. 1984. Grazing and pasture management. Eastern Bay of Plenty Deer Farmers Association Seminar. Ministry of Agriculture and Fisheries, Rotorua.

Rattray P.V. 1977. Effect of lambing date on production from breeding ewes on pasture allowance and intake. Proceedings NZ Grassland Association 30: 98-I 07. 